\title{
Drawing Video Game Mental Maps: From Emotional Games to Emotions of Play
}

By exploring emotions at play in video game experiences, we sought to analyze how people interact with digital spaces in everyday life. Taking a somewhat different view than much of the literature in the field of video game studies, we examined emotions that were created from users' experience of games, rather than focusing on game design and gameplay. To that end, we based our analysis on 38 video game mental maps drawn by 26 people. We successively analyzed the topic, the structure, and the experiential and emotional meaning of each of the mental maps. Thus, we explored the diversity of emotions that participants linked to video games, and examined the mental maps in relation to what the respondents said about how and why they chose to draw a particular video game. Our work shows the importance of looking beyond the analysis of affects and gameplay, and of examining the emotions produced by the video game experience, along with what they can tell us about the role of games in individual and collective spatial experiences and sociability. Everything doesn't happen on the screen, and what is lived within the game also depends on what is lived in the physical space of the player. In other words, video games aren't emotional in themselves, but there are significant video game experiences that contribute to the structuration of individuals.

KEYWORDS: video games; computer games; mental maps; digital space; digital geography; emotions; cultural practices

\section{ACKNOWLEDGEMENTS}

The research presented in this paper is part of the LUDESPACE collective research program on video game users and practices in France. It obtained funding from the French National Research Agency (ANR JCJC 2011-2014). Throughout this paper, I use plural pronouns such as "we" and "our" to recognize the contribution of my LUDESPACE colleagues to this work. I wish to warmly thank the different reviewers and editors of this paper for their numerous and relevant comments, which definitely helped enhance my initial version.

\section{INTRODUCTION}

Since THE TERM “CYBERsPace” WAS coined by William Gibson in 1984, digital tools have extensively infiltrated our everyday space, from augmented reality games to interactive road maps. This increasing digital influence on our experience of space has led researchers to argue that it is now necessary to erase the distinction between the real and the virtual, and they consequently speak of geocyberspace (Bakis 1997), code/space (Dodge and Kitchin 2005), hybrid space (de Souza e Silva 2006), or augmented reality (Graham and Zook 2013).
Video games, as a cultural activity strongly supported by the development of digital technologies and mobile media, seem a relevant starting point to observe the nature of those spaces. As stated by Shaw and Warf, "simple dichotomies like player and game, or real and virtual space, fail to do justice to the depth and extent to which digital technologies have penetrated minds and bodies in contemporary capitalism" $(2009,1339)$. With growing media coverage and the success of augmented reality games such as Pokémon Go, video games are now particularly well 
established as a cultural activity in society. According to the CEO of Niantic, the studio behind the game, the number of Pokémon Go players worldwide was estimated to have exceeded 65 million in the spring of 2017 (www. businessinsider.fr/us/pokemon-go-65-million-monthly-active-players-2017-4). The international analysis firm Newzoo estimated that the global turnover of the video game industry in 2018 will reach almost $\$ 138$ billion USD (newzoo.com/wp-content/uploads/2018/08/Global_ Games_Market_2018.png). But despite their widespread use, there have been very few studies on the geographies of video games; geographers have mostly focused on spatial representations within games (e.g., Magnet 2006; Shaw 2010), their potential educational uses (e.g., Adams 1998; Gaber 2007), or, more rarely, the video game industry itself (Aoyama and Izuchi 2003; 2006; Johns 2006). There is therefore a need to study the geographies "produced by the digital" (Ash, Kitchin, and Leszczynski 2018, 35) in video games, by looking beyond the analysis of devices and technologies and their design, and examining how they are actually used and domesticated (Berker et al. 2006).

As Ash and Gallacher point out regarding the study of video games, "there is a need for continued methodological innovation in order to capture and document the complex interrelations between gestures, discourses, feelings, affects, among other categories and frames of sense"
(2011, 363). The aim of this paper is to respond to this need, both theoretically and methodologically. We aim to show the value in analyzing the way digital spaces are actually produced and experienced by their users. To that end, studying the emotions involved in the video game experience seems to us a relevant starting point. It allows us to focus on the players, rather than analyzing game design or gaming devices as previous researchers have done. At the same time, our approach also takes into account the context in which these emotions occur, and their effects on individuals. In other words, by tackling the issue from an emotional perspective, it is possible to situate video game practices socially and spatially, and to examine how a particular geographical experience emerges, conjointly produced by the in-game space and the space of the player. To achieve this aim, we used a "mental maps" methodology developed in a research program on video game users and practices in France. The first part of this article presents the theoretical framework of the study, emphasizing the importance of taking into account the diversity of experiences when examining the geography of digital spaces. The second part covers the survey methodology, based on mental maps and semi-structured interviews, used to analyze the emotions produced by playing video games, and the socio-spatial context of the experiences related to them. The final sections discuss the results of the study and the main findings.

\section{EMOTIONS IN GAMES OR EMOTIONS AT PLAY?}

IAN SHAW CLAims THAT "play is relatively under-theorized in cultural studies" (2010, 791). Instead, content analysis has long dominated the study of video games. Geographers and other researchers have focused mostly on spatial representations or game design, while pointing out the need to take into account the player's experience. Our work follows the latter line, by taking the players' emotions as a starting point to analyze the geographical experience of video games.

\section{FROM GAME STUDIES TO PLAY STUDIES}

The field of "Video Game Studies" has historically been dominated by internalist approaches, favoring the study of content and taking either a narratology or a ludolo$g y$ view. Narratologists have focused on the discourse and representations produced by video games, whether through text or images (Fuller and Jenkins 1995; Aaserth 1997; Salter 2011). By contrast, ludologists have focused on analysis of game mechanics and gameplay, arguing that what distinguishes video games from other media or cultural products is the nature of the human/machine interaction (see, for instance, Frasca 1999; Stockburger 2006). This debate is still significant, and above all testifies to the importance given to the analysis of the medium itself rather than to the way it is used. ${ }^{1}$ However, neither of these approaches say much about the way this cultural medi$\mathrm{um}$ is received or about the experiences of the players. Of course, the latter are mentioned, but often independently of their individual, social, or geographical characteristics. Even when talking about immersion or the emotions produced by video games, researchers usually focus on either 
very personal analyses (Krzywinska 2015; Gong, Hassink, and Maus 2017), or techniques for producing emotions and commitment (Frome 2007; Juul 2007). However, some authors acknowledge that "elements such as the physical qualities of the gaming device as well as the social space surrounding the game are part of the game space" (Stockburger 2006, 87), but do not necessarily describe them.

In contrast to these internalist approaches, other studies, first appearing in the early 2000s, showed that video games are played in a variety of contexts, and by players with varying levels of commitment; hence there is a diversity of gaming experiences. These include works by Taylor (2006) and Berry (2012) on massively multiplayer online role-playing games (MMORPGs), ethnographies of Second Life (Boellstorff 2008; Lucas 2013), research on e-sports (Taylor 2012), and work on cheating in games (Consalvo 2007). In the case of online multiplayer games such as Lineage and World of Warcraft, for instance, Steinkuehler (2006) observes how different communities of players interpret the rules and game framework differently. Dyer-Witheford and de Peuter (2009) also describe how digital workers, usually based in Asian-Pacific countries, are paid to play games in order to accumulate ingame resources that will then be resold to other players for real money, and whose experiences of virtual worlds are radically different from the consumer-players of the European and North American markets. Similarly, both Boellstorff (2008) and Lucas (2013) have shown the variations in users' experiences of digital spaces in the online game Second Life, and the different ways they have of "inhabiting" virtual worlds. Thus, because video game practices can vary widely from one individual to another, and because they are geographically and socially situated in the individual's way of living and social space (Rufat, Ter Minassian, and Coavoux 2014; Coavoux and Gerber 2016), Mathieu Triclot (2013) argues for the development of a field of "Play Studies." Video games are, above all, experiences, which depend as much on the socio-spatial context in which they take place (Boutet 2012) as on the players' biographical trajectories (Coavoux and Gerber 2016).

Thus, as observed by Ash, there are no pre-determined meanings of the images and representations in a video game, but rather actualized meanings that occur in the context of their use: "Experiencing an image is an embodied event. The signification of the image is not determined in advance of it being viewed, but is made performatively in the singular moment of this or that viewing by differently located and contextualised bodies" (2009, 2107). Ash therefore recommends that video games should be considered based not only on how they represent reality, but also on their geographical function and their capacity to produce space. Shaw (2010) thus borrows from the psychoanalyst Donald Winnicott the notion of "transitional space" to characterize these video game spaces: a place of transition and encounter between oneself and the real world, a place in which the subjectivity of the former meets the political and social organization of the latter. For instance, Shaw looks at how war-themed video games bear the imprint of the American military-industrial complex. But while he questions the nature of digital spaces as transitional spaces (by looking at their aesthetics and narrative content), we look at what is happening in these digital spaces. This involves not only being attentive to user/ screen interactions-whether through messages, feedback, or affects that circulate from one to the other-but also to the context of video game practices, what we have called elsewhere the "space of the player" (Rufat and Ter Minassian 2011), by studying the emotions that come into play during these experiences.

\section{EMOTIONS AT PLAY IN VIDEO GAMES}

Video games produce many affects, that is, "precognitive and embodied (re)actions" that structure the geographical experience of video games (Shaw and Warf 2009, 1333). As Ash (2009) points out, the player is affected by a game's audio, visual, and sometimes tactile stimuli (the vibrating motors in the game controllers). In addition, some living-room devices such as the Kinect or Wii have popularized dance, music, or sports video games that force players to use their own moving bodies (and not just their hands) to control activity on the screen. At the same time, some major video game studios have put considerable effort into the scriptwriting of their games, and called upon real actors to portray game characters to reinforce the realism of the dialogues. In 2018, the second Emotional Games Awards took place in France. What kinds of emotions are produced by these affects and realistic game narratives?

While it may seem relevant to study the affects of a game session, the concept of emotion is necessary to characterize this geographical experience from the point of view of the players and to understand how they incorporate it in 
their biography. It is insufficient to simply describe a player's experiences; we must also look at how these experiences arise and structure players' sociability and practices. For instance, for Fiske (1989), pleasure is not only an act of passive consumption, it is also a form of activity that engages the individual in their environment. Emotions are thus part of the process of construction and interpretation of the world and our spatial experiences. As described in Emotional Geographies (Davidson, Bondi, and Smith 2007), they contribute to the way we structure our spatial practices and represent and categorize the world. Individuals do not have emotions; they produce them in situations of social and spatial interaction (Bareither 2017). In this way, emotions are not just about the feeling that is experienced: they also concern the context in which they were experienced and made possible. As observed by Davidson and Milligan, "While we attribute emotional agency or capacity to a surprising range of external sources-saying, for example, that low clouds make us gloomy, while blue skies raise our spirits-our heart-felt articulations of emotion, themselves, acknowledge their interactional quality" $(2007,524)$.

\section{MAPPING THE GAME, MAPPING}

FOR MANY CATEGORIES of video games, the map is a crucial element. For example, in adventure games, role-playing games, and shooting games, the player uses it to navigate through virtual spaces. In city-builder games and war games, maps support planning or conquest. Players sometimes create their own maps to facilitate navigation, to help other players, or to produce personal artistic works. ${ }^{2}$ The widespread involvement of maps in video gaming suggested to us that maps would be a good medium for examining the geographical experiences of players. Griffin and McQuoid (2012) identify three main uses of cartography in understanding human emotions: maps can be used to represent emotions (e.g., a map of world happiness); they can elicit emotions during reading; and they can be used to collect emotional data and show "emotional associations individuals have with certain places" $(2012,297)$. Our work is in line with the latter, as we used video game mental maps to interview players about their experiences and the socio-spatial context in which those experiences happened.
Our hypothesis is therefore that the analysis of emotions related to playing video games cannot be reduced to the study of activities and affects that occur during a video game session, but must also take into account the attachments developed by the player, during their life, towards the many items related to playing video games-not only objects and devices, but also digital spaces or particularly striking events. As stated by Owain Jones, "emotions are systemic and interact constantly with our conscious and unconscious selves, memories and environment" (2007, 205). Hence, to understand the emotions related to video games, we should study games as a leisure activity that can be embodied in various situations and that can be given many different meanings according to the player's motives and biography. In other words, emotion in a video game is not just about activation of a few gameplay mechanisms; it arises from the geographical experience in which the activity takes place, while contributing to its particular meaning.

\section{THE EXPERIENCE}

\section{MENTAL MAPS AS "GRAPHICAL AUTOBIOGRAPHIES"}

Mental map methodology has been recognized in geography since the pioneering work of Lynch (1960) and of Gould and White (1974), although it has seldom been applied in the field of video games and digital worlds. However, mental maps enable interviewees to tell a story, or to relate a geographical experience. ${ }^{3}$ Thus, a map offers more than a simple description of the digital space, instead "shaping it with meaning," in the words of Pearce (2008, 21). According to Antoine Bailly, mental maps are "graphical autobiographies" (quoted in Avry 2012); in other words, when people draw a place, they are not only describing it, they are also saying something about themselves. They are expressing a spatial experience, and their attachment to places and emotions.

Thus, we believe that mental maps can complement semi-structured interviews, helping respondents describe particular experiences and emotions aroused by certain

2. Some can be found on the Internet, for instance at mapstalgia.tumblr.com.

3. For a general discussion of theoretical and methodological issues of mental maps see Avry (2012). 
activities (or specific moments) of their life as a video game player. As observed by Gould and White, "Our memory, far from holding every sensory impression from our environment, selects and retains only a small portion" (1974, 43). For this reason, we looked for a method that could activate respondents' memories and lead them to describe their relationship with a particular game or their memory of a particular experience, without any preconceived ideas about the type of emotions that these virtual experiences may arouse. We aimed to achieve a balance in how the players described their digital space experience between "involvement in" and "detachment from" space (Pearce $2008,21)$, encouraging them to focus on relating their experience of the space rather than on accuracy and precision of the drawing. Hence, the aim of our video game mental maps was not for interviewees to give an accurate account of the characteristics of a video game space, but rather to describe how they experienced it. In this way, the mental maps brought out memories, emotions, and thoughts linked to specific moments or experiences in particular social or spatial contexts, which would have escaped us in conversations about other aspects of game activities.

\section{VIDEO GAME MENTAL MAPS METHODOLOGY}

We employed our mental maps methodology in LUDESPACE, a collective research program on video game users and practices in France, funded by the French National Research Agency (2011-2014). ${ }^{4}$ Our project involved interviews with 26 people (11 women and 15 men), ${ }^{5}$ conducted in 2013 and 2014. The age of the respondents ranged from 17 to 56 years, and their profiles varied: some were not employed (two retired, one university student, one high-school student), while others were, with a diversity of professions and levels of qualification (civil servant, police officer, doctoral student, teacher, real estate agent, programmer, architect, etc.).

The LUDESPACE research program included: (1) a population-wide quantitative survey on video game uses $(2,042$ adults aged $18+$ and 500 teenagers aged 11 to 17); (2) about 30 semi-structured interviews with players about their past, present and future video game practices; (3) audio/video recordings of nine video game sessions at players' home. Since the LUDESPACE research focused on video game users in general, and not only on intensive video game players, our sample also included respondents with varied levels of commitment. While some of them claimed to be experienced players (like Jeanne, ${ }^{6}$ a 22 -yearold student, or Michel, a 34-year-old programmer), others described themselves as "former" intensive players (Dominique, a 34-year-old sales representative), or as casual players (Guy, a 33-year-old senior civil servant), or even non-players (Chantal, a 47-year-old retired teacher).

During the semi-structured interviews, respondents were asked to draw one or more video game spaces of their choice. Their hands were filmed while drawing, and they were encouraged to talk about what they were doing, so that we could analyze not only the topic but also the structure of the drawing and the discourse. Our approach was guided by the example of Avry (2012): namely, that the analysis of mental maps is not about accuracy (they are not a test) or aesthetics, but about examining the topic of the map, the structure of the map, and its experiential and emotional meaning. Our analysis of each mental map's topic focused on the interviewee's choice of video game (what did they draw?). The analysis of the structure of the mental map focused on the way the mental map was drawn (how did they draw it?): what was depicted, in what order, and the elements (characters, landscape, on-screen directions, etc.) that the participant considered relevant to explain the geographical experience and emotions related to the drawn space. Finally, our examination of the experiential and emotional meaning of the mental map focused on the motivations, justifications, and explanations given by the respondent for choosing a particular drawing or game (why did they draw it?). Our project ultimately included 38 mental maps drawn by 26 people. Two people did not participate in the mental map exercise; the reasons for their refusal are discussed below. Some of the maps were very different than what a map, even a mental map, is normally expected to be. We decided to keep them in the corpus, not based on objective criteria (scale, orientation, etc.), but because they are the way some of our respondents

\footnotetext{
4. For more details, see: citeres.univ-tours.fr/spip.php?article1267. I would particularly like to thank Manuel Boutet and David Gerber, who contributed significantly to the qualitative part of the fieldwork and its analysis. 5. The respondents were selected according to their participation in either the quantitative survey or the recordings of video game sessions, or according to their
specific background as players (since we were looking for diversity).
}

6. For ethical reasons, all interviewees are anonymized in this paper. 
understood the instructions they were given to draw a video game space.

\section{PITFALLS AND LIMITATIONS}

One could argue that drawing a space is not necessary in order to talk about it. In fact, most of our interviewees found the instructions difficult to understand at first: what does it mean to "draw" a video game space? What space should they draw? Should be it the map of the virtual world, one place in particular, the character's environment, or even the interface that appears on their TV, smartphone, or computer screen (as in Figure 1)? Nonetheless, we asked them to create mental maps because we considered that it would likewise be very difficult for our interviewees to answer questions such as "tell me about your emotions when you played that game or when you played with your siblings or your friends."

Still, our choice of approach led two interviewees refusing to draw video game mental maps. From what we learned in their interviews, it appears that their refusal was due less to their inability to draw maps by hand, than to the fact that they didn't feel committed to video games as a leisure activity. For example, Lionel acknowledged that he spent some time playing video games as a child, but that he was no longer very interested, even if he sometimes played with his two daughters or during long journeys. He now preferred car races, comic books, and superhero movies. The other, Chantal, considered that video games were overall a waste of time, although she did play Sudoku on her smartphone. Hence, for both of them, drawing video game mental maps did not seem relevant, because they
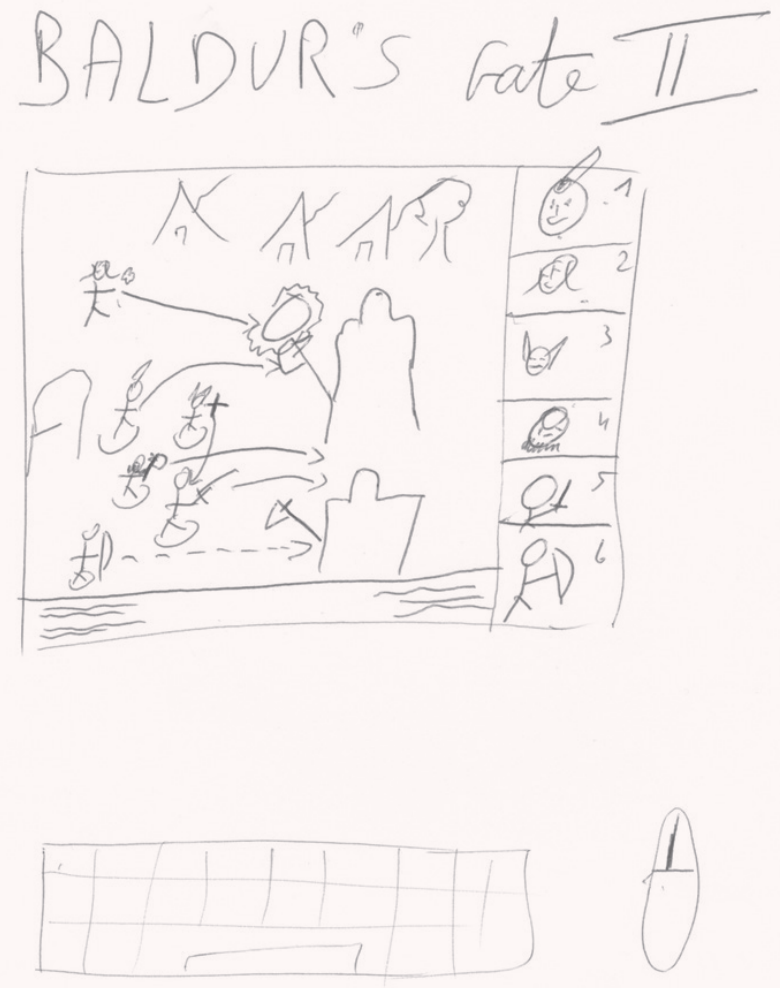

Figure 1. Georges's view of the space in the game and the space of the interface.

have little experience to call upon, or because they didn't consider that video games to be an important part of their cultural practices or social activities. By contrast, the other interviewees were very keen to do so. These different attitudes towards the mental map exercise are in themselves an objective indicator of the importance of video games in some people's lives, in terms of their leisure and cultural activities, their social networks, and their everyday experience of digital spaces.

\section{EMOTIONS AT PLAY IN VIDEO GAMES}

An overall anAlysis of the corpus shows a great diversity of subjects drawn in the mental maps (29 different titles or video game categories across the 38 maps), including both well-known and obscure titles, generic categories (basketball games, strategy games), and even one personal creation by a respondent who studied game design and programming. It also shows that the most commonly depicted genres in our corpus, such as "platform games" (10 out of 38) and "puzzles and solitaire games" (6 out of 38), are those with the poorest virtual space. In the former, digital space is usually a network of discontinuous "levels" or "stages," sometimes without transition zones. The latter include games such as Solitaire, Sudoku, or Crosswords, which usually have no geographical space other than the screen of the device on which they are played.

\section{ABOUT MENTAL MAP TOPICS: WHAT PEOPLE DREW AND WHY}

Having looked above at which video games our interviewees chose to draw, we turned next to how they explained their choices during their interviews. Interviewees identified five main reasons for their choices, some of which were directly related to emotions (Figure 2). 


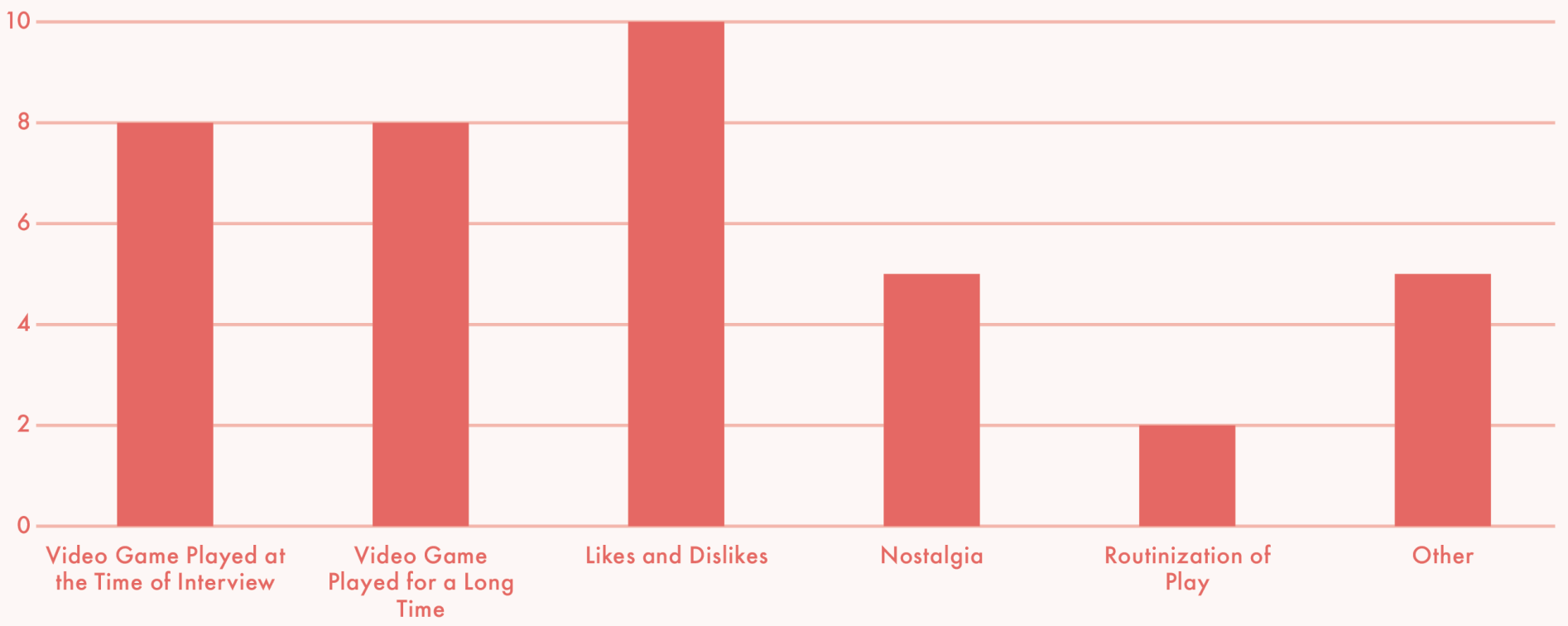

Figure 2. Reasons interviewees chose certain video games for their mental maps.

The first reason for drawing one game in particular was that it was the game the interviewee had been playing around the time of the interview. Not surprisingly, when asked to draw a video game mental map, some of the players drew the one that immediately came to mind because they had just been playing it. For instance, Guy, who is a casual video game player, drew a "runner" game that he had been playing the day before the interview (although he could not remember its name). However, as shown in Figure 2 , most people preferred to draw a game that had more emotional significance for them (aggregating the "video games played a long time," "likes and dislikes," and "nostalgia" categories).

The second reason was that it was a game that the interviewee had played for a long time. Drawing it thus underlines the fact that it had particular significance in their experience as a video game player. For example, Patrick drew a map of CounterStrike (Figure 3), even if he now plays it less than soccer video games, because he had played it for a long time and had significant social and spatial experiences related to it. He managed

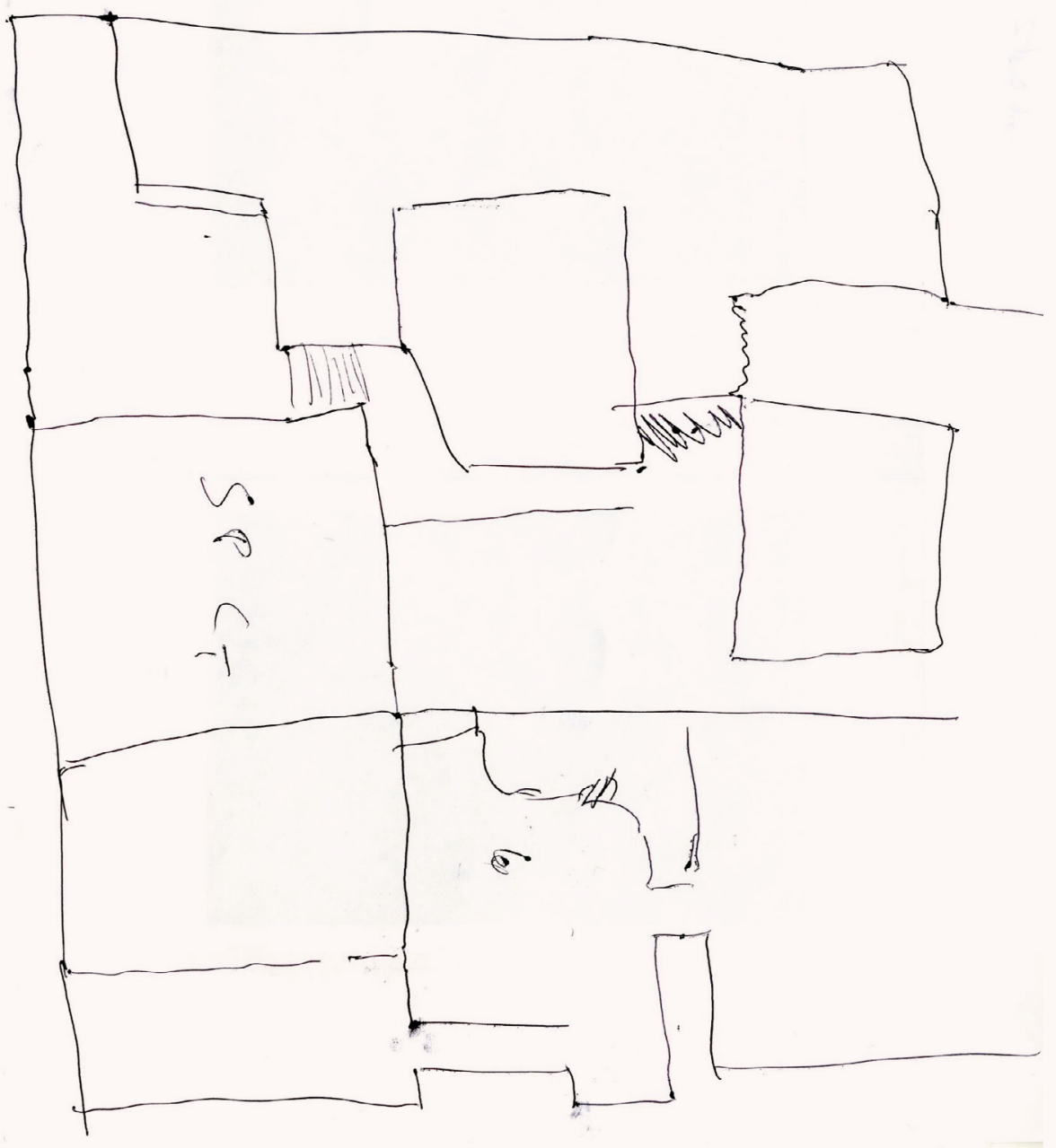

Figure 3. Patrick chose to draw "Dusł2" in CounterStrike. 
his own team and had taken part in several meetings and competitions (sometimes involving more than 50 players) in different cities.

The third motivation was related to likes and dislikes of a video game genre, which appeared 10 times out of 38. Of course, most of the players drew games they liked. Some of them chose to draw not one game in particular, but a genre: for example a platform game, a car racing game (see Figure 4), or a strategy game (Figure 5).

The fourth motivation was nostalgia. Here again, the video games chosen were those with special significance for the player, not necessarily because of the amount of time spent playing them, but because they were played under very specific circumstances. For example, they were the games played during childhood, or played with brothers or sisters, or with a tournament team, etc. Thus, Céleste decided to draw a video game from the Legend of Zelda franchise, because she still had fond memories of playing it when she was a child.

By contrast, the fifth motivation concerned video games that were played in a very routinized way. These are the games that people play not because they particularly like them or because they are emotionally attached to them, but because they play them often, and in very specific situations: for example during journeys, or in the evening while watching TV, or while walking the dog, which was the case of Claude. He was not an intensive video game player, but he plays Solitaire a lot, not because he particularly likes it (actually, he prefers car racing games), but simply because it fits conveniently in his time-space of video game activity. Thus, video games do not always produce emotions, and they are not always played because they resonate with the player's biography. Nevertheless, the mental maps drawn by our respondents show that the majority of experiences they related had emotional significance.

\section{POSITIVE AND NEGATIVE EMOTIONS AT PLAY}

A closer look at the emotions produced by playing video games reveals their diversity. Using the video game mental maps and what participants told us about them while drawing, we identified seven different emotional relationships between people and games in our corpus, three positive and four negative. The first is pleasure: obviously, people who like video games take pleasure in playing, and

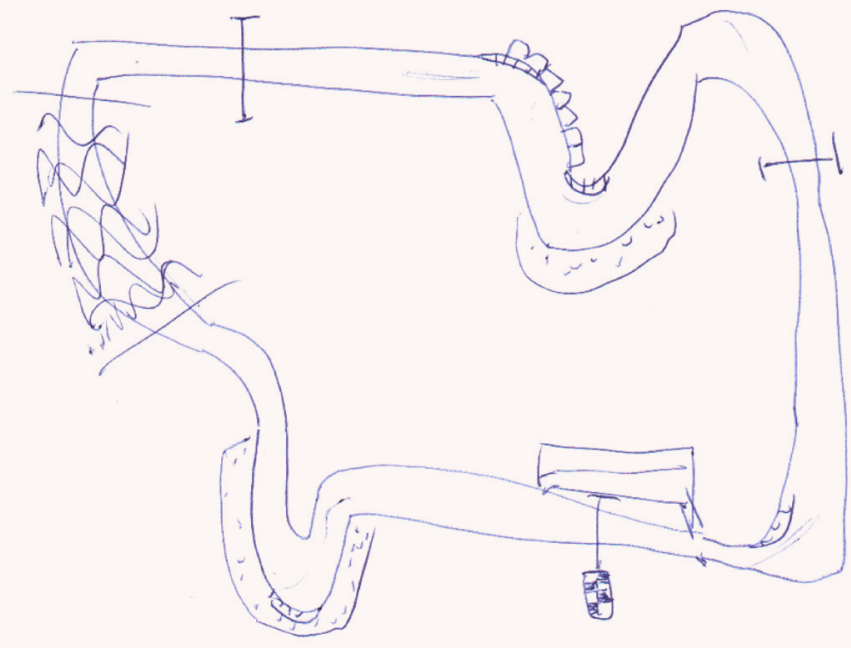

Figure 4. Lucas likes to play car racing games.

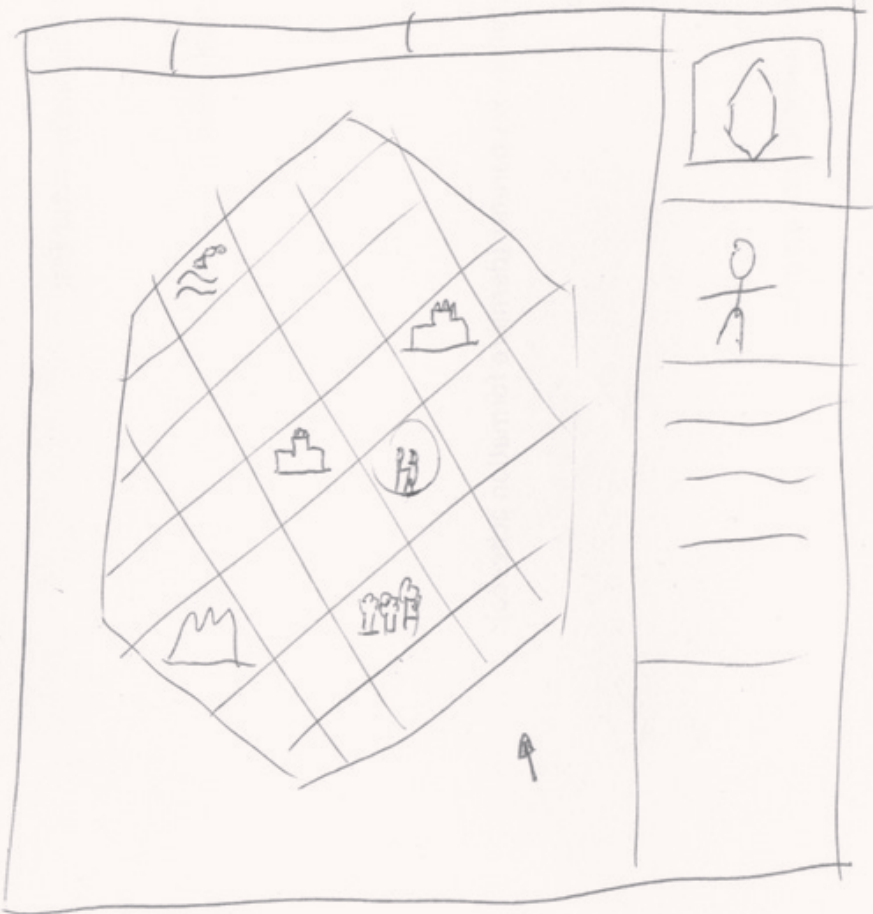

Figure 5. Marc's personal taste for strategy games, like Civilization.

when asked, many people (e.g., Dominique and Michel) told us that they could not imagine stopping playing video games in the near future because the games and their related culture were an important part of their leisure and social life. For example, even if Dominique describes himself as a "former" intensive player, he still continues to visit and read specialized websites and magazines, staying informed of releases and news of the industry. 
Another emotion linked to pleasure is joy, but whereas pleasure describes the activity as a whole (one does or does not like playing video games), joy describes a sense of elation evoked by significant or unique experiences. This is illustrated best by Nelly, who drew a mental map of one particular place in the virtual world of The Legend of Zelda: Ocarina of Time (Figure 6). While drawing the main character of the game with a staff in front of a closed door surrounded by pillars and torches, she recalled very precisely the moment during her childhood when she managed to open that particular door she was struggling with: "I found myself stuck in the first room of the dungeon and you had to use a stick to light a torch in order to open the door. I talked about how I found out how to do it all through dinner!" Here, the drawing itself is less important than what Nelly says about it. It could be any character or any door from numerous roleplaying or adventure games. Nevertheless, this mental map had a special meaning for Nelly because it reminded her of a positive emotion she experienced through this game; she even said, "For me, it was really a new world. . . That's when my life changed." Her statement could make us smile, but we could also take it seriously and acknowledge that playing video games can be an opportunity to experience new worlds, widen cultural horizons, and possibly be the source of rich experiences.

In our context, nostalgia is also a positive emotion, in that it allows players to relive intense video game experiences, and may motivate them to continue playing. Thus, Laurence remembered playing Aladdin during childhood: "I used to play it with my sister, otherwise she couldn't finish the game." In her case, playing video games was

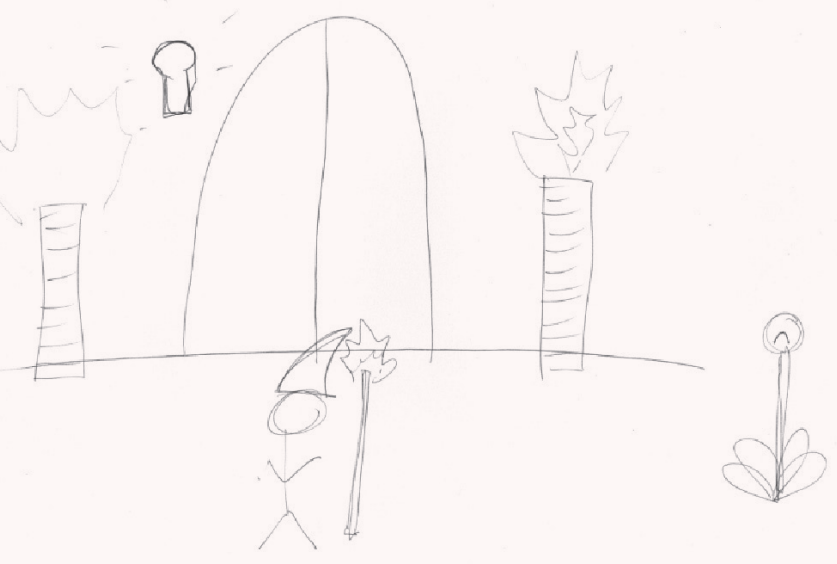

Figure 6. Nelly struggling to solve a problem in The Legend of Zelda: Ocarina of Time. connected to her relationship with her sibling, and to their shared leisure activities when they were children.

However, the range of emotions and geographical experiences related to video games is not limited to positive ones. Respondents' discourses about the maps they drew also revealed negative emotions, beginning with fear. For instance, Céleste told us that she was afraid of spiders, even digital ones: "I'm also scared in Zelda when there are spiders. I jump up, I scream. And I run away. But . . . but I run away screaming. . . . In Zelda, generally I used to play alone, and when all of a sudden they would come out, like that, usually I would jump a good nine feet in the air before fighting." In her case, the emotional experience of fear in a virtual world is seemingly just as strong as what she would have experienced in the physical world. While she described The Legend of Zelda as her "fetish game," she was still able to talk about a negative experience she had had many years before, which she probably wouldn't have mentioned during the interview without the use of the video game mental map.

Anxiety is another negative emotion we identified in relation to video game experiences, occurring, for instance, when a player gets lost. This was the case of Yann, a highschool student who told us about his feeling of loneliness and loss in the roleplaying video game Skyrim, because the in-game space was too huge and because he struggled with the in-game map: "At the beginning, I didn't know what it pictured, but generally it was the nearest dungeon. But besides that, to find one's way . . . as soon as you move, it spins around. I couldn't understand where I was. I looked for the map every time." Interestingly, he did not produce a mental map of that video game, but chose to draw a different one, with which he had more positive emotions.

Contrary to what advertisements and video game producers tell us, boredom can also be quite common. Among our interviewees, many, like Amelie, played some games because they had to (for example to spend time with a friend, brother or sister, etc.) but without enjoying it: "I'm completely lost, I mean, I'm going round in circles in the level. And my character he will ... he can't do anything because he just keeps going round in circles. Well, it's . . it's tragic. He's supposed to climb on the roofs, but he always kills himself. And that's it. I can't master it. I don't like it." It confirms the observations of Coavoux and Gerber (2016) that in some cultural activities, sociability comes before taste. Some people do not necessarily play video games 
because they like them, but because they want to be with their friends or family.

Finally, guilt was also experienced by a couple of our interviewees. For example, Chantal, a housewife with three children, did not like video games very much (unlike her children). As we mentioned earlier, she considered video games as a waste of time, unlike reading books or singing with a choir (leisure activities she enjoyed on a regular basis). But, at the same time, she revealed that she played Sudoku on her smartphone every morning for about twenty minutes, after her husband left the house to go to work, and before doing the housework. She explained that that this short video game session was the only time in the day she could take for herself (rather than taking care of the family and their home), but she still did not permit herself to play too long.

\section{VIDEO GAME PLAY: A SYNECDOCHICAL EXPERIENCE?}

Finally, our analysis of the structure of the mental maps shows that they can be grouped into two broad families. In the first, the respondents mainly drew specific "operationable" features in the video game space: items, characters, and elements of the game with which the player can interact. Interaction with these items makes the action possible, but they are not themselves necessarily representative of the overall setting, landscape, or story. In the second group, by contrast, the players drew items, characters, or parts of the set that represent larger portions of the game,

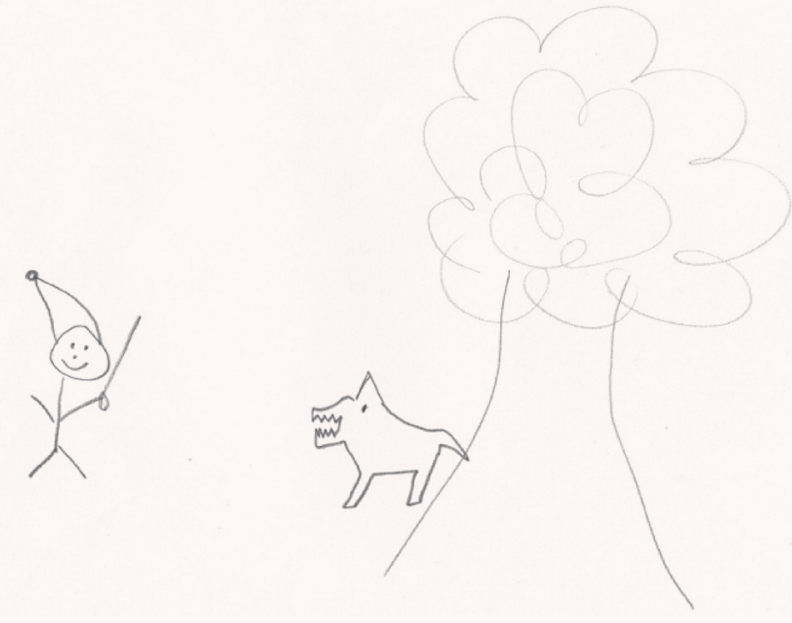

Figure 7. "I'll draw a tree on the side, to represent the world, so to speak" (Céleste drawing The Legend of Zelda). using a few example elements to demonstrate the whole. Thus, one player drew a monster to symbolize all the enemies the character has to confront; another drew a tree to represent the forest and natural environment (Figure 7).

In our view, the mental maps of this second category express a "synecdochical" approach. A synecdoche is a figure of speech that allows the whole to be expressed through the part. Thus, a sail seen on the horizon is not just a sail, it is a boat. According to Détrie, the synecdoche involves interpretation, whereby "experience takes precedence over content" $(2006,795)$. It is because I know that a boat has a sail that I can say that a sail on the horizon indicates the presence of a boat. Hence, the synecdoche engages the speaker to represent the world as they experience it from their own perspective (Détrie 2006, 796). In the case of our participants, these synecdochical maps show how the player experiences virtual space.

The mental map thus gives players the opportunity to express a certain perspective on the video game space, based on their particular experience. Unlike mental maps that highlight the operationable, the synecdochical mental map is an opportunity for the respondent to express emotions, feelings, or judgments about the aesthetic aspect of virtual spaces. They can share their opinions on the quality of the game experience, whether environments are beautiful, poetic, or enchanting, or on the contrary too vast or too oppressive. While the operationable map thus places the video game experience within a utilitarian or pragmatic relationship to virtual space, the synecdochical one places it within an emotional or aesthetic relationship. In the words of Silas, one of our younger respondents, "You can't rely on drawing. It's much more beautiful.” Moreover, for respondents who believed that they couldn't draw very well, the synecdochical property of the mental map can have a compensatory function. Céleste, for example, drew only one sketch of a tree instead of drawing a whole forest, claiming that the latter was beyond her drawing skills.

However, it is not always possible to reduce each respondent to a single attitude or a single map category, since some, like Lucas, made mental maps that fall within both of the above-mentioned categories. In those cases, we believe that the players most involved in playing video games navigate more easily from one category to another, and can draw on a greater diversity of geographical experiences of virtual spaces. 
VIDEO GAME EXPERIENCES WITHIN

BIOGRAPHICAL TRAJECTORIES OF PLAYERS

We aimed to show how mental maps could be a useful tool to encourage people to express emotional experiences linked to their past or present involvement in cultural activities and social relationships related to digital spaces. One limitation of our method is that the mental maps thus produced are not easy to understand without the comments of the people drawing them. In other words, "stories don't come from the map," as Mark Denil puts it $(2016,7)$. All maps require interpretation, and in our case, we sometimes needed to know which digital space (or which part of it) had been drawn, or even which video game had been chosen, particularly as some of them were not immediately recognizable. As Avry (2012) points out, a mental map does not show space as it is, but space as it is perceived. For instance, Françoise's mental map of the video game World of Warcraft can seem very puzzling. This online role-playing game depicts a fantasy world where players explore dungeons, slay monsters, and collect treasures. Françoise decided to draw not the map of the in-game world (or a portion of it), but rather a portrait of a witch, recognizable by her pointy hat and her broom, items associated with witches in folk culture (see Figure 8).

Françoise is a 56 year-old housewife with three children, with whom she likes to play video games. But she particularly likes drawing and painting, and she is very attracted to fantasy worlds and local folk tales, in which she finds inspiration for her artwork. She always likes to play a witch "avatar" whenever possible, including in World of Warcraft, because the game provides a narrative background (a folk tale) which matches her tastes and can be a source of creativity. Thus, her portrait of a witch is as much a self-portrait of her avatar in World of Warcraft as a way of encapsulating her enjoyment of video games and of drawing fantasy figures, which gives the drawing its synechdochical property. It is a mental map not of one game in particular but of Françoise's "interior world," made up of emotions (attachment to her in-game avatar), culture (fantasy books, folk tales), tastes (drawing, painting, playing video games), and social activities (playing with her sons and friends).

This example shows that, like all other activities, digital activities and spaces can be enmeshed in what the anthropologist Amos Rapoport calls "systems of activities" (1990). That is, that video games hold meaning for individuals in relation to other activities, whether professional or leisure. Thus, Michel is a programmer and draws the game he would like to create, Emma is an architect and draws a city builder game, Etienne plays basketball and draws a basketball game, and Mika likes Solitaire and sometimes plays with traditional cards (in addition to digital ones). Playing video games thus forms a "system" with other activities and contributes to the production of meaningful experiences, and to situating the player both socially and emotionally. In this way, the in-game space and the space of the player conjointly define the place of each singular video game experience in the player's biography and practices. More generally, one way to capture the domestication of a digital technology (Berker et al. 2006) could be to observe its interpenetration with other more established social or cultural practices.

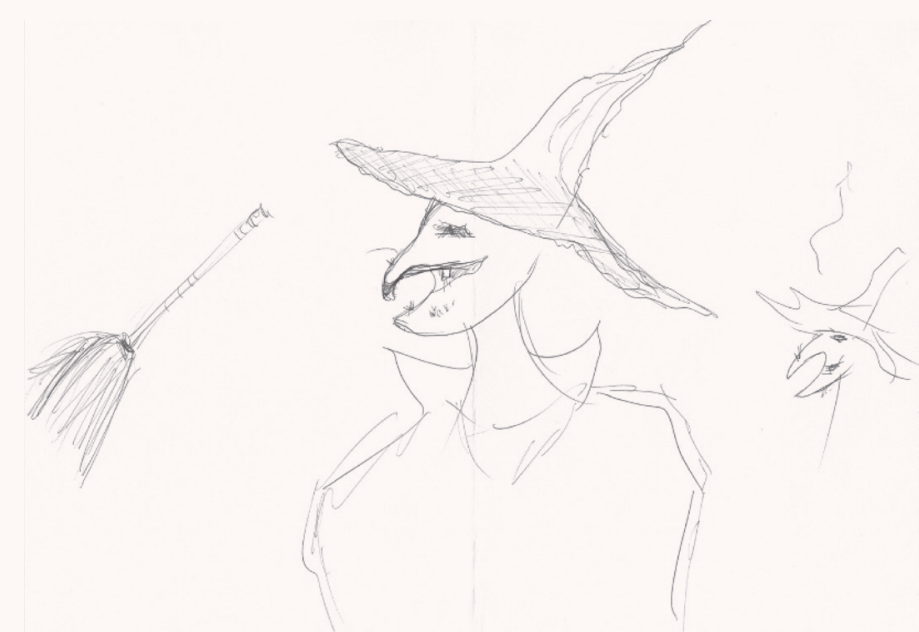

Figure 8. How Françoise depicts herself in World of Warcraft.

Also, as seen above, playing video games is an experience that can be emotional (producing nostalgia, fear, pleasure, boredom, etc.) under certain conditions linked to the socio-spatial context, but that no game is emotional in itself. Here we fully agree with Bareither's (2017) ethnographic analysis, in which he clearly shows that the pleasure resulting from playing violent games is not inherent to the device or the game itself. It is a production of meaning (guilt or, on the contrary, the pleasure of transgression) partly linked to the game environment, whether online through a video channel or side-by-side with a friend in the same room. The emotion arises not only from the game device but also from the environment of its use, the space of the player. One can thus assume that the same game will not produce the same emotions for each individual, but that they will depend on the time-space in 
which it is played. An analogy can be made here with the movie experience, which varies not only from one individual to another but also according to the expectations of the same movie watched in different contexts. Thus, for Jullier, a "good movie" is one that has "fulfilled its role," which varies in different situations $(2012,39)$. This also shows the importance of going beyond the basic analysis of affects and of looking at the emotions an experience produces, along with what they reveal about the place of video games in systems of activities, social relations, and personal or collective experiences.

Thus, in one-third of the cases studied in our work, the geographical experiences described are constitutive of "player trajectories" (Coavoux 2008), showing that the latter are based on both capitalization of experiences in certain video game genres, and on opportunities offered by particular occasions or events in the players' lives. As pointed out by Hockey, Penhale, and Sibley (2007), objects, images, and sounds of the past are not simple stimuli; they are constitutive of the social time and space of the present. Thus, memory, nostalgia, and even regret or frustration, were common themes in the discourse of our interviewees. This could be a bias of the survey, as the interviews encouraged a retrospective account of players' backgrounds, sometimes leading them to choose and draw games that had been discussed earlier.
However, a dozen other cases also show that these video game experiences involve sociability through play, whether with family members or friends. Coavoux and Gerber (2016) highlighted the importance of this aspect in the way the activity is shared and constructed, which cannot always be seen solely in terms of taste or affinity for a particular game genre. This is confirmed by our findings, namely that people can enjoy playing a video game not only for its intrinsic qualities, but also because it is an opportunity to spend a pleasant evening with people they like. This was the case for Yann, a 19-year-old high-school student, who played or had played games (Dofus, League of Legends) because his friends played, while his personal tastes (especially for manga and Japanese roleplaying games) would lead him to prefer other types of games, which he played on his mobile phone. Analysis of the features (Krzywinska 2015) or the affective design (Ash 2012) of video games is clearly essential to understanding the techniques used by developers and publishers to design objects producing affect, in order to capture the attention of their public and to boost consumption. But at the same time, as pointed out by Nemorin (2017), affects should no longer be considered as simple expressions of individual emotion; their meaning is co-constructed by the individual and the social context in which they take place. In the case of Yann, pleasure, an emotion aroused by video games, was not a result of these player/machine affects and interactions; for him, video games were only a pretext for a shared social experience with his friends.

\section{CONCLUSION}

The AIM OF THIS STUdy was to investigate geographical experiences of video games, by focusing on the emotions produced in relation to playing them. To that end, we used mental maps of digital spaces to get our respondents to describe their emotional relationship with certain video games, and to place those in the more general context of their other activities. Drawing maps was a way to make people talk about the uniqueness of their experience, which means that the discourse related to the mental map was as important in our analysis as the mental map itself. The fact that individuals agreed to draw a mental map of a video game reflects their high involvement in gaming (even for respondents who now spend less time playing). Thus, the geographical experience of video games here is the product of the convergence between a certain type of commitment to playing video games and certain categories of games.

Our study has three main results. First, it demonstrated that spatial experiences of video game play are diverse. This is an important contribution to the field of video game studies, which until now mainly focused, as seen in the first part of this article, on the analysis of human/ machine interactions and gameplay. We invite others to better take into account the spatial contexts of use, which do participate in the emotional reception and the quality of the spatial experience of a video game. Everything doesn't happen on the screen, and what is lived within the game also depends on what is lived in the physical space of the player. Thus, the geography of video games should 
not be limited to content analysis (which places and spaces are represented in video games and how they are represented) but should also include the analysis of the different spaces of play, whether physical, digital, or hybrid, looking at them in terms of continuity and interpenetration (de Souza e Silva 2006; Graham and Zook 2013) rather than in terms of discontinuity. Further investigation could be conducted to document these relations between the ingame space and the space of the player and how they contribute conjointly to produce singular spatial experiences (Stockburger 2006).

Secondly, our study highlights the quality and diversity of emotions produced by video game practices, underlining their individual and collective dimensions. Digital spaces can produce strong emotions, seemingly as much as physical spaces. These emotions, and the geographical experience that arouses them, contribute to the individualization of digital practices and their inscription into individuals' biographical trajectories, sociability, taste, and activities. At the same time, they are embedded into collective relationships to video game culture and practices, be it with a group of friends with whom one shares certain practices, or a generation of people who grew up with a video game culture and have appropriated some of its icons (as we can see with the numerous mental maps of major characters from video game history, such as Mario or Sonic). Our study shows that the emotions associated with video games can lead to different forms of appropriation of space (embellishing one's home with video game merchandise), sociability (creating or maintaining relationships with friends), or other cultural practices (drawing). In other words, video games aren't emotional in themselves, but there are significant video game experiences that contribute to the structuration of individuals.
Thirdly, the experience of video game spaces is not only about success, performance, or mastering. On the contrary, the spatial experiences described by our interviewees include contemplative experiences, “just-for-fun” exploration (like Nelly, for whom The Legend of Zelda video game series stood out of the crowd because it made possible this kind of playing style), and even sometimes a sense of disorientation or loneliness (like Yann with the roleplaying video game Skyrim, mentioned above). There again is an invitation to go beyond content and gameplay analysis which assume that players' behavior is determined by the gameplay and the device, and to anchor the study of digital worlds in empirical, comprehensive studies of their users (Shaw 2010), beyond the scope of MMORPGs and digital worlds such as Second Life, on which, until recently, most of the research has been focused (Coavoux, Boutet, and Zabban 2016).

Of course, our work doesn't address larger concerns about the risks of everyday life being dehumanized by the digital world, or about its control by digital governmentality (Gardin, Didier and Quentin 2016). But it also helps put these arguments into perspective by exposing the great diversity of actual digital practices of users. In the end, for the people we met, video games produce emotions and geographical experiences, but probably no more or less than other activities. Our analysis highlights the potential diversity of the geographical experiences of virtual worlds, varying between individuals, their practices, and their biographical trajectories, even if this raises the issue of digital divide. In a world increasingly governed by numbers and technology, these diverse experiences and player trajectories show that there is still room for individual agency in regards to what video games and game publishers expect of users; the players can, to a certain extent, produce their own meaning for their digital activities.

\section{REFERENCES}

Aaserth, Espen. 1997. Cybertext: Perspectives on Ergodic Literature. Baltimore: The John Hopkins University Press.

Adams, Paul C. 1998. "Teaching and Learning with Sim City 2000.” Journal of Geography 97 (2): 47-55. doi: $10.1080 / 00221349808978827$.
Aoyama, Yuko, and Hiro Izuchi. 2003. "Hardware Gimmick or Cultural Innovation? Technological, Cultural and Social Foundations of the Japanese Video Game Industry." Research Policy 32: 423-444. doi: 10.1016/S0048-7333(02)00016-1. 
Aoyama, Yuko, and Hiro Izuchi. 2006. "Industry Evolution and Cross-sectoral Skill Transfers: A Comparative Analysis of the Video Game Industry in Japan, the United States and the United Kingdom."

Environment and Planning A 38 (10): 1843-1861. doi: 10.1068/a37205.

Ash, James. 2009. "Emerging Spatialities of the Screen: Video Games and the Reconfiguration of Spatial Awareness." Environment and Planning A 41 (9): 2105-2124. doi: 10.1068/a41250.

2012. "Attention, Video Games and the Retentional Economies of Affective Amplification.” Theory, Culture E Society 29 (6): 3-26. doi: $10.1177 / 0263276412438595$.

Ash, James, and Lesley Anne Gallacher. 2011. "Cultural Geography and Video Games.” Geography Compass 5/6: 351-368. doi: 10.1111/j.1749-8198.2011.00427.x.

Ash, James, Rob Kitchin, and Agnieszka Leszczynski. 2018. "Digital Turn, Digital Geographies?" Progress in Human Geography 42 (1): 25-43. doi: 10.1177/0309132516664800.

Avry, Loïc. 2012. "Analyser les Conflits Territoriaux par les Représentations Spatiales : une Méthode Cognitive par Cartes Mentales." PhD diss., Université de Rennes 2.

Backis, Henry. 1997. "From Geospace to Geocyberspace. Territories and Teleinteraction." In Developments in Telecommunication: Between Global and Local, edited by Edward Mozley Roche and Henry Bakis, 15-49. Singapore: Ashgate.

Bareither, Christoph. 2017. “'That was so mean :D’ - Playful Virtual Violence and the Pleasure of Transgressing Intersecting Emotional Spaces." Emotion, Space and Society 25: 111-118. doi: 10.1016/j. emospa.2016.12.005.

Berker, Thomas, Maren Hartmann, Yves Punie, and Katie Ward. 2006. Domestication of Media and Technology. Maidenhead: Open University Press.

Berry, Vincent. 2012. L'Expérience Virtuelle: Jouer, Vivre, Apprendre dans un Jeu Vidéo. Rennes, France: Presses Universitaires de Rennes.
Boellstorff, Tom. 2008. Coming of Age in Second Life. Princeton, NJ: Princeton University Press.

Boutet, Manuel. 2012. "Jouer aux Jeux Vidéo avec Style. Pour une Ethnographie des Sociabilités Vidéoludiques." Réseaux 173-174: 207-234. doi: 10.3917/res.173.0207.

Coavoux, Samuel. 2008. "La Socialisation aux Jeux Vidéo en Ligne. Carrière des Joueurs et Espace Social du Jeu." Master's thesis, ENS Lettres et Sciences Humaines.

Coavoux, Samuel, Manuel Boutet, and Vinciane Zabban. 2016. "What we Know About Games: a Scientometric Approach to Game Studies in the 2000s." Games and Culture 12 (6): 563-584. doi: $10.1177 / 1555412016676661$.

Coavoux, Samuel, and David Gerber. 2016. "Les Pratiques Ludiques des Adultes entre Affinités Electives et Sociabilités Familiales.” Sociologie 7 (2): 133-152. doi: 10.3917/socio.072.0133.

Consalvo, Mia. 2007. Cheating: Gaining Advantage in Video Games. Cambridge, MA: MIT Press.

Davidson, Joyce, and Christine Milligan. 2007. "Embodying Emotion Sensing Space: Introducing Emotional Geographies.” Social \& Cultural Geography 5 (4): 523-532. doi: 10.1080/1464936042000317677.

Davidson, Joyce, Liz Bondi, and Mick Smith. 2007. Emotional Geographies. Burlington, VT: Ashgate.

Denil, Mark. 2016. “Storied Maps.” Cartographic Perspectives 84: 5-22. doi: 10.14714/CP84.1374.

Détrie, Catherine. 2006. "La Production de Sens Synecdochique : Relation Partitive et/ou Phénomène de Saillance ?" In La Relation Partie-Tout, edited by Georges Kleiber, Catherine Schnedeker, and Anne Theissen, 783-797. Paris: Editions Peeters.

Dodge, Martin, and Rob Kitchin. 2005. "Code and the Transduction of Space." Annals of the Association of American Geographers 95 (1): 162-80. doi: 10.1111/j.1467-8306.2005.00454.x. 
Dyer-Witheford, Nick, and Greg de Peuter. 2009. Games of Empire. Minneapolis: University of Minnesota Press.

Fiske, John. 1989. Understanding Popular Culture. London: Routledge.

Frasca, Gonzalo. 1999. "Video Games of the Oppressed.” Master's thesis. Georgia Institute of Technology.

Frome, Jonathan. 2007. "Eight Ways Video Games Generate Emotions." Proceedings of the 2007 DiGRA International Conference: Situated Play, 831-835. Tokyo: The University of Tokyo.

Fuller, Mary, and Henry Jenkins. 1995. "Nintendo and New World Travel Writing: a Dialogue." In Cybersociety: Computer-Mediated Communication and Community, edited by Steven G. Jones, 57-72. London: Thousand Oaks.

Gaber, John. 2007. "Simulating Planning: Sim City as a Pedagogical Tool." Journal of Planning Education and Research 27 (2): 113-121. doi: 10.1177/0739456X07305791.

Gardin, Jean, Sophie Didier, and Aurélie Quentin. 2016. "Liberty, Equality, IT. Algorithmic Governmentality and Spatial Justice." Justice Spatiale/Spatial Justice 10: 1.

Graham, Mark, and Matthew Zook. 2013. “Augmented Realities and Uneven Geographies: Exploring the Geo-Linguistic Contours of the Web." Environment and Planning A 45 (1): 77-99. doi: 10.1068/a44674c.

Griffin, Amy L., and Julia McQuoid. 2012. "At the Intersection of Maps and Emotion: the Challenge of Spatially Representing Experience." Kartographische Nachrichten 62: 291-299.

Gong, Huiwen, Robert Hassink, and Gunnar Maus. 2017. "What does Pokémon Go Teach us About Geography?” Geographica Helvetica 72: 227-230. doi: 10.5194/gh-72-227-2017.

Gould Peter, and Rodney White. 1974. Mental Maps. Harmondsworth, UK: Penguin.
Hockey, Jenny, Bridget Penhale, and David Sibley. 2007. "Environments of Memory: Home Space, Later Life and Grief." In Emotional Geographies, edited by Joyce Davidson, Liz Bondi, and Mick Smith, 135-145. Burlington VT: Ashgate.

Johns, Jennifer. 2006. "Video Games Production Network: Value Capture, Power Relations and Embeddedness." Journal of Economic Geography 6 (2): 151-180. doi: 10.1093/jeg/lbi001.

Jones, Owain. 2007. "Ecology of Emotion, Memory, Self and Landscape." In Emotional Geographies, edited by Joyce Davidson, Liz Bondi, and Mick Smith, 205-218. Burlington, VT: Ashgate.

Jullier, Laurent. 2012. Qu'est-ce qu'un bon Film? Paris: La Dispute.

Juul, Jesper. 2007. "A Certain Level of Abstraction.” Proceedings of the 2007 DiGRA International Conference: Situated Play, 510-515. Tokyo: The University of Tokyo.

Krzywinska, Tanya. 2015. “Gaming Horror’s Horror: Representation, Regulation, and Affect in Survival Horror Video Games.” Journal of Visual Culture 14 (3): 293-297. doi: 10.1177/1470412915607924.

Lucas, Jean-François. 2013. “De l'Immersion à l'Habiter dans les Mondes Virtuels. Le Cas des Villes dans Second Life.” PhD diss., Université de Rennes 2.

Lynch, Kevin. 1960. The Image of the City. Cambridge, MA: MIT Press.

Magnet, Shoshana. 2006. "Playing at Colonization. Interpreting Imaginary Landscapes in the Video Game Tropico." Journal of Communication Inquiry 30 (2): 142-162. doi: 10.1177/0196859905285320.

Nemorin, Selena. 2017. "Affective Capture in Digital School Spaces and the Modulation of Student Subjectivities." Emotion, Space and Society 24: 11-18. doi: 10.1016/j.emospa.2017.05.007.

Pearce, Margaret Wickens. 2008. "Framing the Days: Place and Narrative in Cartography." Cartography and Geographic Information Science 35 (1): 17-32. doi: $10.1559 / 152304008783475661$. 
Rapoport, Amos. 1990. "Systems of Activities and Systems of Settings." In Domestic Architecture and the Use of Space, edited by Susan Kent, 9-20. Cambridge: Cambridge University Press.

Rufat, Samuel, and Hovig Ter Minassian. 2011. “Espace et Jeu Vidéo." In Les Jeux Vidéo comme Objet de Recherche, edited by Samuel Rufat and Hovig Ter Minassian, 66-87. Paris: Questions théoriques.

Rufat, Samuel, Hovig Ter Minassian, and Samuel Coavoux. 2014. "Jouer aux Jeux Vidéo en France. Géographie Sociale d'une Pratique Culturelle." L'Espace Géographique 43: 308-323. doi: 10.3917/ eg.434.0308.

Salter, Mark B. 2011. “The Geographical Imaginations of Video Games: Diplomacy, Civilization, America's Army and Grand Theft Auto IV." Geopolitics 16 (2): 359-388. doi: 10.1080/14650045.2010.538875.

Shaw, Ian Graham Ronald. 2010. "Playing War.” Social and Cultural Geography 11 (8): 789-803. doi: 10.1080/14649365.2010.521855.
Shaw, Ian Graham Ronald, and Barney Warf. 2009.

"Worlds of Affect: Virtual Geographies of Video Games." Environment and Planning A 41 (6): 13321343. doi: 10.1068/a41284.

de Souza e Silva, Adriana. 2006. "From Cyber to Hybrid: Mobile Technologies as Interfaces of Hybrid Spaces." Space and Culture 9(3): 261-278. doi: 10.1177/1206331206289022.

Steinkuehler, Constance. 2006. "The Mangle of Play." Games and Culture 1 (3): 199-213. doi: $10.1177 / 1555412006290440$.

Stockburger, Axel. 2006, "The Rendered Arena. Modalities of Space in Video and Computer Games." PhD diss., University of the Arts, London.

Taylor, T. L. 2006. Play Between Worlds. Cambridge, MA: MIT Press.

. 2012. Raising the Stakes. Cambridge, MA: MIT Press.

Triclot, Mathieu. 2013. "Game Studies ou Etudes du Play?” Sciences du Jeu 1. doi: 10.4000/sdj.223. 